\title{
Rectal distention increases the frequency and duration of transient lower esophageal sphincter relaxations in anesthetized dogs - a putative rectoesophageal reflex
}

\section{Distensão retal aumenta a duração do relaxamento transitório do esfíncter esofagiano inferior em animais anestesiados - reflexo reto-esofagiano}

Jose Ronaldo Vasconcelos Graça ${ }^{1}$. Jose Ricardo Cunha Neves ${ }^{1}$. Sidney Wendell Goiana da Silva ${ }^{1}$. Willy Okoba $^{1}$.

1 Universidade Federal do Ceará (UFC), Sobral, Ceará, Brasil.

\begin{abstract}
Introduction: The esophagus is subject to frequent reflux of gastric contents as a normal phenomenon during episodes of transient lower esophageal sphincter relaxation (tLESR), responsible too, for pathologic reflux. However, pathologic reflux is mostly associated with reflux of acid contents. Distending the stomach provokes an increase in frequency of tLESR. Objective: To investigate the effect of distending the rectum on the tLESR and possible involved pathways. Methods: Forty four (Protocol: 096/07) street dogs were selected and divided into respective protocols: Rectal distention (RD), Gastric distention (GD), RD+GD, Atropine + RD, Hexamethonium + RD, Baclofen + RD, Bilateral Pudendal nerve section+RD and Spinal cord transection + RD. We determined and compared the tLESR of each group and subjected data to statistical analysis. Values of $p<0.05$ were regarded as statistically significant. Results: RD provoked a significant increase in the tLESR just as GD, with RD+GD provoking the highest value of tLESR. This increase in tLESR due to RD was prevented in $A+R D, B+R D$, Bilateral Pudendal nerve section $+R D$ and Spinal cord transection+RD but not Hexamethonium+RD protocols. Conclusion: RD is a significant inducer of an increase in tLESR with participation of muscharinic and GABA $\beta$, sensitive and spinal cord neurons, but not nicotinic receptors.
\end{abstract}

Keywords: Esophago-gastric junction. Rectum. Dogs.

\section{RESUMO}

Introdução: O esofago é sujeito a episódios frequentes e fisiológicos de refluxo durante o intervalo do relaxamento transitório do esfíncter esofágico inferior (tLSER). Ao mesmo tempo, o tLSER é responsável pelo refluxo patológico, envolvendo conteúdo ácido. A distensão gástrica (GD) provoca aumento de episódios de tLSER. Objetivo: Investigar o efeito da distensão retal (RD) sobre tLSER e os mecanismos envolvidos. Métodos: 44 cães de rua foram aleatoriamente distribuídos conforme os protocolos respectivos: RD, GD, RD+GD, Atropina (A)+RD, Hexametônio+RD, Baclofeno (B)+RD, secção bilateral do nervo pudendo+RD e secção total da corda espinhal +RD. Comparamos os dados de tLSER de cada grupo e submetemos à analise estatística. Valor $p<0,05$ foi determinado como significante. Resultados: RD provocou aumento significado do tLESR, semelhante à GD, enquanto $\mathrm{RD}+\mathrm{GD}$ resultou em valores ainda maiores de aumento do tLESR. O aumento do tLESR foi abolido nos seguintes protocolos: A+RD, $\mathrm{B}+\mathrm{RD}$, secção bilateral do nervo pudendo+RD e secção total da corda espinhal $+\mathrm{RD}$, mas não no protocolo Hexametônio $+\mathrm{RD}$. Conclusão: RD provoca aumento significado do tLESR em animais sedados e envolve a participação muscarinica, GABA $\beta$, vias sensoriais ascendentes e eferentes. Não há participação dos receptores nicotínicos.

Palavras-chave: Junção esofago-gástrica. Reto. Cães.

Corresponding author: José Ricardo Cunha Neves, Universidade Federal do Ceará, Faculdade de Medicina, Rua Gerardo Rangel, 100, Derby, Sobral, Ceará. CEP: 62042-280. Telefone: +55 88 3611-8000. E-mail: josericardoneves@gmail.com

Conflict of interests: The authors have no conflicts of interest to declare.

Received: 05 Dec 2017; Revised: 08 Dec 2018; Accepted: 08 Dec 2018. 


\section{INTRODUCTION}

The esophagus is subject to frequent reflux of gastric contents despite the activity of major antireflux barriers which protect it from deleterious effects of reflux: the crural diaphragm and the lower esophageal sphincter (LES). ${ }^{1}$ Physiologically, reflux of gastric contents into the esophagus is a normal phenomenon, occurring primarily during episodes of transient lower esophageal sphincter relaxation (tLESR). In patients with gastroesophageal reflux disease (GERD), tLESR is the dominant mechanism involved in pathologic reflux. In fact, the tLESR frequency does not differ notably between healthy individuals and GERD patients, although tLESRs are more likely to be associated with acid reflux in GERD patients. ${ }^{2}$

The major stimulus for tLESR is the post-prandial gastric distention, via activation of a reflex pathway involving mechanoreceptors located in the subcardial area, vagal afferents, nucleus of the tractus solitarius (NTS) in the brainstem, as well as inhibitory efferents to the LES. ${ }^{3}$ In addition to this inhibitory reflex, other inhibitory reflexes originating from the small intestine or the colons also influence the behaviour of the esophago-gastric junction, either directly or by modulating gastric tonus. ${ }^{4,5}$ For instance, healthy individuals subjected to voluntary obstipation present a gastric emptying delay of test meals. ${ }^{6}$ In addition, a revision of literature shows that the prevalence of GERD symptoms in patients with inflammatory bowel disease is approximately $54 \%,{ }^{7}$ an index which increases in patients with dominating constipation symptoms vis-a-vis diarrheic subjects. ${ }^{8}$ Probably this phenomenon is attributed to fermentation of undigested starch by colonic microbioma which generates short-chain fatty acids and hydrogen ${ }^{9}$ that elicit viscerovisceral feedback in healthy subjects, ${ }^{3}$ provoking a distention of the proximal stomach thus triggering tLESR. ${ }^{10}$

In pre-clinical studies with dogs, it was observed by esophageal manometry and $\mathrm{pH}$ monitoring that they possess a capacity for spontaneous GER during tLESRs, of similar characteristics to that of the human being. ${ }^{11}$ Since gastric distention and colonic dilation due to gas from undigested starch can trigger tLESR, the aim of the present study was to investigate whether: i) mechanical distention of a rectal balloon alters the frequency of tLESR in dogs ii) the possible pathways responsible for this phenomenon.

\section{MATERIALS AND METHODS}

\section{Animals}

Forty four (44) healthy adult male mongrel (street) dogs (from 12 to $18 \mathrm{~kg}$ ) were used in our protocols. They were monitored over an 18-hour period up to the end of the experiments, which consisted of fasting for 16 hours, before undergoing experimental protocols that lasted up to 2 hours. Natural day-night exposure, fasting, handle and care issues were strictly adhered to, respecting ethical principles. All animals had access to water ad libitum until 2 hours before the experiments. All procedures were approved by the local Ethical Committee for Animal Experiments (Protocol: 096/07).

\section{Measurement of transient lower esophageal sphincter relaxations}

We adopted the technique proposed originally by Dent, but perfected by Murray and cols. ${ }^{12}$ Animals were sedated with ketamine/xylazine $\left(10 / 20 \mathrm{mg} / \mathrm{Kg}\right.$ - IM; UNIVET ${ }^{\circledR}$ São Paulo/BAYER ${ }^{\circledR}$, São Paulo, Brazil). Additional doses were administered to maintain the palpebral reflex inhibited whenever needed. An eight-lumen Dent sleeve catheter was introduced per os to measure intra-gastric, LES and esophageal pressures. The catheter had four side-holes radially distributed at $90^{\circ}$ from each other and used to monitor the LES-pressures, 3 side-holes notably at 3,8 and $13 \mathrm{~cm}$ proximal to the LES were used to record the esophageal pressures, and one sidehole $5 \mathrm{~cm}$ distal to the LES to record intra-gastric pressures. The stomach was insufflated with air via the central tube. The catheter set up was perfused with tap-water $(0.5 \mathrm{~mL} /$ min) using a low-compliance manometric perfusion pump - Viote System ${ }^{\circledR}$, São Paulo, SP-Brazil. An air-perfused tube was orally introduced and positioned in the pharynx to register swallowing signals. All signals were amplified and acquired on a personal computer at $10 \mathrm{~Hz}$ (PowerLabSystem, ADInstruments $^{\mathrm{TM}}$, Bella Vista, NSW, Australia). Three ml of distilled water was injected into the pharynx through the pharyngeal catheter to induce swallows.

\section{a. Study Protocols}

A summary of the protocols has been illustrated in Figure 1.

\section{Protocol I $(n=4)$}

Immediately after a 45-minute basal period, the stomach was insufflated with air $(50 \mathrm{ml} / \mathrm{Kg})$ during two minutes. Subsequently, the LES and esophageal pressures were continuously monitored for 45 minutes. This technique has been used by other authors as a reliable means of triggering tLESR in $\operatorname{dogs}^{13}$ (Figure 1).

\section{Protocol II $(n=4)$}

After the end of the basal period, 4 animals underwent a rapid and sustained rectal distention, by insufflating a latex balloon up to a volume of $5 \mathrm{ml} / \mathrm{Kg}$, followed by monitoring the intra-gastric, LES and esophageal pressures over 45 minutes (Figure 1).

\section{Protocol III $(n=5)$}

After the basal period, we insufflated the stomach with air $(50 \mathrm{ml} / \mathrm{Kg}$ ) during two minutes and monitored the intragastric, LES and esophageal pressures for 45 minutes. This procedure was followed with the distention of the rectum, by insufflating the positioned latex balloon at a fixed and quick rate, $(5 \mathrm{ml} / \mathrm{Kg})$. Subsequently, gastric, LES and esophageal pressures were monitored over 45 minutes (Figure 1). 


\section{b. Neurohumoral mechanisms}

\section{Pharmacological protocol}

In a separate group, animals were subjected to protocol II, 30 minutes after, either Atropine $(0.15 \mathrm{mg} / \mathrm{kg}, \mathrm{n}=4)$, hexamethonium $(10 \mathrm{mg} / \mathrm{kg}, \mathrm{n}=4)$ or Baclofen $(7.0 \mu \mathrm{g} / \mathrm{Kg}$, $\mathrm{n}=3$ ) was administered (i.v. bolus) (Figure 1).

\section{Surgical protocol}

Four animals underwent bilateral section of the pudendum nerves, while another 4 were submitted to a lumbar spinal cord transection (between L3-L4), before both groups undergoing protocol II. (Figure 1).

Figure 1. Illustration summarizing the experimental protocols (time bars not drawn to scale). After the basal period, the animals were submitted to a gastric (GD), rectal (RD) or gastric+rectal distention $(\mathrm{GD}+\mathrm{RD})$ with air or a latex balloon; respectively for the protocols I, II and III. In protocols involving neurohumoral mechanisms investigation, the animals were pre-treated with intravenous doses of (a) atropine $(0.15 \mathrm{mg} / \mathrm{Kg})$, (b) hexamethonium $(10 \mathrm{mg} / \mathrm{Kg})$, (c) baclofen $(7.0 \mathrm{~g} / \mathrm{Kg})$, (d) surgical bilateral pudendum nerve section (Ø pudendal nn.) or (e) lumbar spinal cord transection (Ø medulla tra.) prior to rectal distention.
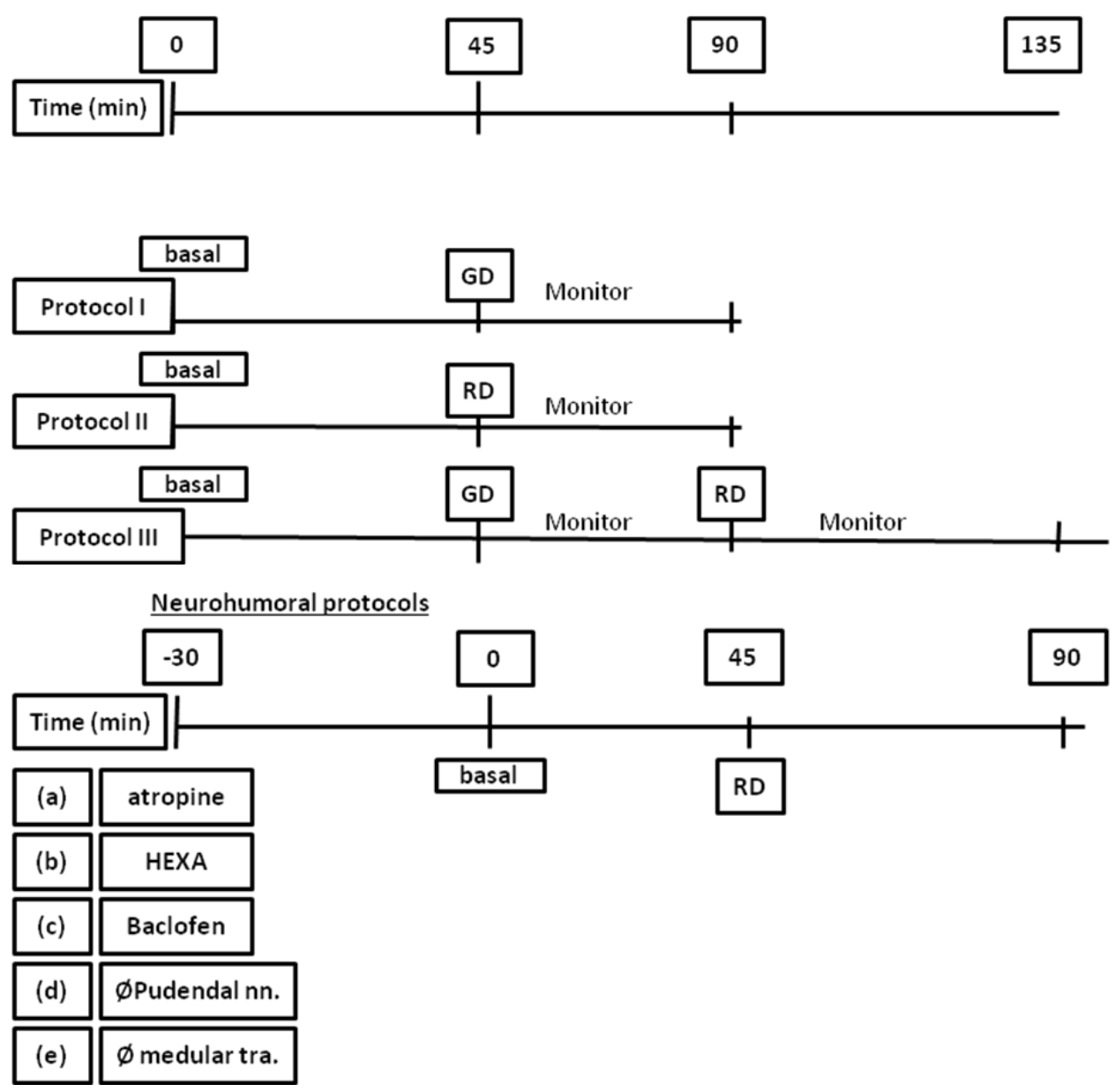

\section{Data and Statistical Analysis}

Gastroesophageal motility index were calculated as described by Jensen. ${ }^{14}$ Transient lower esophageal sphincter relaxation was defined as a decrease in lower esophageal sphincter pressure with the following characteristics: (a) a decreasing rate of at least $1 \mathrm{mmHg} / \mathrm{s}$; (b) absence of a swallow, 2 seconds before tLESR's onset; (c) difference in abdominal pressure $<2 \mathrm{mmHg}$ sustained for at least 3 seconds. ${ }^{2}$ The basal LES pressure was defined as the mean pressure of the four radialsided holes, relative to the respective intra-gastric pressure.
The latency was defined as the interval between the onset of gastric or rectal distention and the onset of the first tLESR. Rate of tLESR (events/h), gastric and LES pressures $(\mathrm{mmHg})$, latency (minutes) and tLESR duration (seconds) were calculated with reference to the respective mean of basal period.

Data was expressed as mean \pm S.E.M. Thereafter, we used Student's t-test when comparing two groups, while we adopted ANOVA with regard to more than two groups. Values of $p<0.05$ were regarded as statistically significant. 


\section{RESULTS 1}

\section{Gastric and rectal distention}

As illustrated in Table 1, gastric distention (GD) significantly increased the frequency of tLESR $(6.0 \pm 1.0 v s 2.8 \pm 0.8$ events $/ \mathrm{h})$, but did not modify gastric or LES pressure. Furthermore, GD significantly decreased the latency but increased the duration of tLESR.

While rectal distention (RD) provoked a significant increase in the frequency of tLESR, it did not evoke changes in gastric or LES pressure. Similarly, RD decreased $(p<0.05)$ the latency but increased the duration of tLESR.

Ultimately, GD+RD evoked the highest recorded rate of tLESR $(9.5 \pm 2.5$ events $/ h)$, whether compared to the basal period (2.8 \pm 0.8$)$, gastric $(6.0 \pm 1.0)$ or rectal distention alone (5.2 \pm 1.8$)$. This protocol significantly decreased the latency, increased the duration of tLESR; however, it didn't change neither the gastric, nor the LES.

\section{Neurohumoral mechanisms}

\section{a. Pharmacological studies}

Pre-treatment with atropine prevented the increase in the rate of tLESR due to RD, but decreased the LES pressure (15 \pm 3.2 ), as Table 2 shows. Atropine pre-treatment however, evoked no changes in the gastric pressure, latency, or the duration of tLESR.
Pre-treatment with hexamethonium did not prevent the increase in tLESR due to $\mathrm{RD}(5.6 \pm 2.3$ events $/ \mathrm{h})$. This treatment decreased both LES and gastric pressures, but did not modify the effects of RD on either the latency or the duration of tLESR.

Pre-treatment with baclofen prevented the increase in events of tLESR due to RD. Despite both LES and gastric pressure increasing $(p<0.05)$ following baclofen pre-treatment, it did not modify the effect of RD on the latency or duration of tLESR.

\section{b. Neural pathways}

As illustrated in Table 3, sectioning of the pudendum nerves bilaterally prevented the increase in frequency of tLESR due to $\mathrm{RD},(2.0 \pm 1.7$, vs $2.4 \pm 0.9$, vs $5.2 \pm 1.8$ events $/ \mathrm{h}, p>0.05)$ respectively, whereas the LES and gastric pressures remained unchanged. However, this procedure prevented both a decrease $(p<0.05)$ in the latency of the lower esophageal sphincter, as well as an increase in the duration of tLESR, when compared to basal and sham operated animals.

Lumbar spinal cord transection prevented the increase in the frequency of RD-induced tLESR, when compared to basal values and sham animals $(2.5 \pm 1.5$, vs $2.4 \pm 0.9$, vs $5.2 \pm 1.8$ events/h, $p>0.05$ ). The procedure did not change the LES or gastric pressures. Just as pudendum nerve transection, this procedure prevented both a decrease in the latency and an increase in the duration of tLESR due to RD.

Table 1. Effects of gastric distention, rectal distention or gastric and rectal distention combined, on the rate (per hour), latency before the first episode ( $\mathrm{min}$ ) and mean duration (sec) of transient Lower Esophageal Sphincter Relaxations (tLESR) and mean resting Lower Esophageal Sphincter (LES) and Intra-Gastric pressures, in anesthetized dogs.

\begin{tabular}{llllll}
\hline Groups/Period & tLESR/hr & Latency (min) & Duration(s) & \multicolumn{2}{c}{ Pressure (mmHg) } \\
\cline { 5 - 6 } & & & & LES & Gastric \\
\hline Basal (n=26) & $2.8 \pm 0.8$ & $29.0 \pm 4.0$ & $17.0 \pm 0.8$ & $23.5 \pm 2.5$ & $3.3 \pm 0.5$ \\
GD (n=5) & $6.0 \pm 1.0^{*}$ & $3.5 \pm 1.5^{*}$ & $44.5 \pm 5.1^{*}$ & $20.5 \pm 3.5$ & $4.5 \pm 1.5$ \\
RD (n=5) & $5.2 \pm 1.8^{*}$ & $6.8 \pm 2.5^{*}$ & $42.5 \pm 5.4^{*}$ & $20.3 \pm 2.5$ & $2.7 \pm 1.7$ \\
GD+RD (n=4) & $9.5 \pm 2.5^{*}$ & $4.5 \pm 1.5^{*}$ & $46.6 \pm 4.5^{*}$ & $23.8 \pm 4.7$ & $4.0 \pm 2.5$ \\
\hline
\end{tabular}

a. The total number of tLESR recorded in all animals over the initial $45 \mathrm{~min}$ was considered as Basal ( $\mathrm{n}=26$ ), before being subjected to gastric distention (GD) by insufflating air through an oral-intragastric placed canula (gastric distention, $\mathrm{n}=5)$. * $\mathrm{p}<0.05$ vs. Basal ('t' -Student Test).

b. The total number of tLESR recorded in all animals over the initial 45min was considered as Basal ( $\mathrm{n}=26$ ), before being subjected to rectal distention (RD) by insufflating with air, a rectal positioned-latex balloon $(\mathrm{RD}, \mathrm{n}=5)$. ${ }^{*} \mathrm{p}<0.05$ vs. Basal ('t'-Student Test).

c. The total number of tLESR recorded in all animals over the initial $45 \mathrm{~min}$ was considered as Basal ( $\mathrm{n}=26$ ), before being subjected to gastric distention by insufflating air through an oral-intragastric placed canula, followed by rectal distention by insufflating with air, a rectal positioned-latex balloon ( GD+RD, n=5). ${ }^{*} \mathrm{p}<0.05$ vs. Basal ('t'- Student Test). 
Table 2. Effects of Atropine, Hexamethonium and Baclofen pre-treatment on the rate (per hour) of transient Lower Esophageal Sphincter Relaxations (tLESR), latency before the first episode (min), mean duration (sec) of transient Lower Esophageal Sphincter Relaxations (tLESR) and mean resting Lower Esophageal Sphincter (LES) and Intra-Gastric pressures (IGP) due to Rectal distention in anesthetized dogs.

\begin{tabular}{llllll}
\hline & & & & \multicolumn{2}{c}{ Pressure (mmHg) } \\
\cline { 5 - 6 } Groups/Period & tLESR/hr & Latency (min) & Duration(s) & LES & IGP \\
\hline Basal (n=26) & $2.8 \pm 0.8$ & $29.0 \pm 4.0$ & $17.0 \pm 0.8$ & $23.5 \pm 2.5$ & $3.3 \pm 0.5$ \\
$\mathbf{S + R D}(\mathbf{n}=\mathbf{5})$ & $5.2 \pm 1.8^{*}$ & $6.8 \pm 2.5^{*}$ & $42.5 \pm 5.4^{*}$ & $20.3 \pm 2.5$ & $3.7 \pm 1.7$ \\
$\mathbf{A + R D}(\mathbf{n}=\mathbf{4})$ & $3.2 \pm 2.0 \#$ & $26.8 \pm 2.5 \#$ & $18.5 \pm 5.4 \#$ & $15 \pm 3.2^{*} \#$ & $4.5 \pm 1.2$ \\
$\mathbf{H + R D}(\mathbf{n}=\mathbf{4})$ & $5.6 \pm 2.3^{*}$ & $8.5 \pm 2.2^{*}$ & $36.5 \pm 13.7^{*}$ & $9.7 \pm 3.5^{*} \#$ & $1.7 \pm 1.6 \#^{*}$ \\
$\mathbf{B + R D}(\mathbf{n}=\mathbf{4})$ & $1.9 \pm 0.9 \#$ & $27.8 \pm 2.3 \#$ & $12.5 \pm 5.4 \#$ & $35 \pm 3.2^{*} * \#$ & $5.5 \pm 1.6 \#^{*}$ \\
\hline
\end{tabular}

$* \mathrm{p}<0.05$ vs. Basal, $-\# \mathrm{p}<0.05$ vs saline.

a. The total number of tLESR recorded in all animals over the initial $45 \mathrm{~min}$ were considered as Basal ( $\mathrm{n}=26)$, before being pre-treated to a dose of Saline (Saline, $\mathrm{n}=5$ ), or Atropine (Atropine, $0.15 \mathrm{mg} / \mathrm{kg}$, i.v, $\mathrm{n}=4$ ). After 30min, RD was executed in the pre-treated group. ${ }^{*} \mathrm{p}<0.05 \mathrm{vs}$. Basal, $-\# \mathrm{p}<0.05$ vs saline -ANOVA followed by Student-Newman-Keuls test, (Basal vs A+RD, S+RD vs A+RD).

b. The total number of tLESR recorded in all animals over the initial $45 \mathrm{~min}$ were considered as Basal $(\mathrm{n}=26)$, before being pre-treated to a dose of Saline (Saline, $\mathrm{n}=5)$, or Hexamethonium $(10 \mathrm{mg} / \mathrm{kg}$, i.v, $\mathrm{n}=4)$. After 30min, RD was executed in the pre-treated group. ${ }^{*} \mathrm{p}<0.05$ vs. Basal, $-\# \mathrm{p}<0.05$ vs saline, ANOVA followed by Student-Newman-Keuls test, (Basal vs $\mathrm{H}+\mathrm{RD}, \mathrm{S}+\mathrm{RD}$ vs $\mathrm{H}+\mathrm{RD}$ ).

c. The total number of tLESR recorded in all animals over the initial 45 min were considered as Basal $(n=26)$, before being pre-treated to a dose of Saline (Saline, $\mathrm{n}=5)$, or baclofen $(10 \mathrm{mg} / \mathrm{kg}, \mathrm{i} . \mathrm{v}, \mathrm{n}=4)$. After $30 \mathrm{~min}$, RD was executed in the pre-treated group. ${ }^{*} \mathrm{p}<0.05$ vs. Basal, $-\# \mathrm{p}<0.05$ vs saline - ANOVA followed by Student-Newman-Keuls test, (Basal vs $\mathrm{B}+\mathrm{RD}, \mathrm{S}+\mathrm{RD}$ vs $\mathrm{B}+\mathrm{RD})$.

Table 3. The effects of bilateral pudendum resection (Ø Pudendal nn.) and medulla transection (Ø medular tra.) on the rate (per hour) of transient Lower Esophageal Sphincter Relaxations (tLESR), latency before the first episode (min), mean duration (sec) of transient Lower Esophageal Sphincter Relaxations (tLESR) and mean resting Lower Esophageal Sphincter (LES) and Intra-Gastric pressures due to Rectal distention in anesthetized dogs.

\begin{tabular}{llllll}
\hline \multirow{2}{*}{ Groups/Period } & tLESR/hr & Latency $(\mathbf{m i n})$ & Duration & \multicolumn{2}{c}{ Pressure $(\mathbf{m m H g})$} \\
\cline { 5 - 6 } & & & & LES & Gastric \\
\hline Basal (n=18) & $2.4 \pm 0.9$ & $31.0 \pm 3.0$ & $15.0 \pm 0.5$ & $22.1 \pm 2.7$ & $3.3 \pm 0.7$ \\
S+RD (n=5) & $5.2 \pm 1.8^{*}$ & $6.8 \pm 2.5^{*}$ & $42.5 \pm 5.4^{*}$ & $20.3 \pm 2.5$ & $3.7 \pm 1.7$ \\
Ø Pudendal nn. + RD (n=4) & $2.0 \pm 1.7 \#$ & $23.0 \pm 1.4 \#$ & $19.5 \pm 7.4 \#$ & $18.0 \pm 0.6$ & $3.7 \pm 2.0$ \\
Ø medular tra. + RD $(\mathbf{n}=\mathbf{4})$ & $2.5 \pm 1.5 \#$ & $22.3 \pm 0.5 \#$ & $17.5 \pm 4.5 \#$ & $23.0 \pm 4.7$ & $2.01 \pm 1.3$ \\
\hline
\end{tabular}

${ }^{*} \mathrm{p}<0.05$ vs. Basal and $\# \mathrm{p}<0.05$ vs. Sham.

a. The animals were subjected to bilateral pudendum nerve resection (Ø Pudendal nn., $\mathrm{n}=4$ ) or false surgery (Sham, $\mathrm{n}=5$ ). Thereafter, the total number of tLESR recorded in the operated animals over the initial $45 \mathrm{~min}$ were considered as Basal (Basal, $n=18$ ). Later, $R D$ was executed in the pre-operated group. ${ }^{*} p<0.05$ vs. Basal, $-\# p<0.05$ vs Sham ANOVA followed by Student-Newman-Keuls test, (Basal vs Ø Pudendal nn.+RD, S+RD vs Ø Pudendal nn.+RD).

b. The animals were subjected to medulla transection (Ø medular tra., $n=4)$ or false surgery (Sham, $n=5)$. Thereafter, the total number of tLESR recorded in the operated animals over the initial $45 \mathrm{~min}$ were considered as Basal (Basal, $\mathrm{n}=18$ ). Later, RD was executed in the pre-operated group. ${ }^{*} \mathrm{p}<0.05$ vs. Basal, $-\# \mathrm{p}<0.05$ vs Sham - ANOVA followed by Student-Newman-Keuls test, (Basal vs $\varnothing$ medular tra.+RD, S+RD vs $\varnothing$ medular tra.+RD). 


\section{DISCUSSION}

Our results showed that like GD, RD provoked a significant increase in the frequency of tLESR, without evoking changes in gastric or LES pressure. The latency of tLESR was significantly decreased, however with a shorter duration, just as similar due to GD. Rectal distention combined with gastric distention $(\mathrm{RD}+\mathrm{GD})$ evoked the highest increase in the frequency of tLESR, but provoked similar results on the latency and duration of tLSER-episode, just as either GD or RD. In a similar fashion, lumbar spinal cord transection as well as bilateral sectioning of the pundendi nerves prevented the increase in frequency of tLESR due to RD. The increase in the frequency of tLESR due to (RD+GD) was prevented by pre-treating our subjects with atropine and baclofen but not hexamethonium.

Conventional manometry is the gold standard in measuring esophageal pressure-characteristics. ${ }^{15}$ Modern and improved manometry modes are readily available with highlight on the solid-state and bio-impendence manometry, which are thought to be more advantageous than the conventional water-perfused manometry. This is due to the fact they are less taxing in maneuvering despite the virtue of offering a high-frequency response thus a higher quality test than that of conventional manometry. However, further studies are warranted to prove that this advantage translates to significant superior results. Our laboratory has utilized the conventional manometry in carrying out other tests in other anterior publications. ${ }^{8}$ As principle, manometry enables continuous measurement of the frequency of tLESR episodes with their simultaneous pressures, leading to a better comprehension of GERD, by identifying tLESR as the main permissive mechanism for GERD. ${ }^{16}$ Using a low-compliance manometric perfusion technique, we obtained results on gastric and LES pressures which were similar to those published by others. ${ }^{3,17}$ Despite past-dated by new and more sophisticated methods, the low-compliance manometric perfusion technique allowed for 'real time' manometry recording, during simultaneous insufflation of the stomach with air, through the central lumen.

For our study model, we selected the dog since liquid and gas reflux patterns in dogs occur during tLESR, in a similar pattern that is permissive to reflux of gastric contents, just as is in humans. ${ }^{11}$ Since esophageal manometric and $\mathrm{pH}$ studies in awake dogs have similar tLESRs' characteristics as to humans, we are aware that a dog, in an awake state would be ideal, since general anesthesia abolishes spontaneous tLSER, unless the stomach is distended with large volumes of fluid..$^{15}$ Due to contention constraints, we sedated all subjects during the entire period of monitoring. Indeed, even under sedation, we recorded a significant increase in tLSER after RD, utilizing initially small air volumes, although the final accumulated volume was higher than that by others who didn't sedate their subjects. ${ }^{17}$

This methodological set up has been utilized before in other published studies. While Palheta ${ }^{8}$ and Lehmann ${ }^{13}$ utilized this method in developing their protocols involving GD in dogs, Youle had earlier proved that a painless RD in dogs elicited significant effect in retarding gastric emptying of a solid meal. ${ }^{7}$ Subsequently, Yin et al not only did utilize the RD protocol in provoking a retard in gastric emptying of solids, but also showed that the retard effect was preventable by prior treatment of subjects with mirtazapine. An increase in retard in gastric emptying is known to increase tLSER, just as GD. ${ }^{3}$ Since RD is capable of provoking an increase in retard of gastric emptying, we researched on its direct effects on the tLSER; without necessary distending the stomach.

As a protective physiological reflex intended to prevent the propulsion of gaseous content to the duodenum, tLSER occurs as a physiological reflex due to increased gastric complacency hence decreasing gastric pressure, following ingestion of a meal or air. ${ }^{3}$ Mechanically distending the stomach triggers tLESR by activating mechanoreceptors or chemoreceptors thought to be located in the subcardial area. ${ }^{17,18}$ These receptors are vital in mediating the postprandial relaxation of the proximal stomach. ${ }^{3}$ For a long time, gastric distention was thought to be the only stimulus for tLESR; by activating the reflex pathway involving the afferent gastro-vagal pathways, brainstem centers harboring, in particular, the nucleus tractus solitarius (NTS) and the inhibitory efferents to the LES. ${ }^{19}$ However, recent publications show that distending the distal gut evokes inhibitory motility patterns of the proximal gut. For instance, infusing lactose or short-chain fatty acids in the proximal colon and its subsequent fermentation results to distention of the colon, which increases the frequency of reflux-associated-tLSER episodes. ${ }^{10}$ Fermentation of sugar or short-chain fatty acid produces gas thought to activate colonic distention-sensitive chemoreceptors. ${ }^{20}$ Activated chemoreceptors in the distended colon consequently release metabolic active peptides such as PYY and OLI, which, besides gas, stimulate mechanical receptors in the sub cardia and subsequently the tLESR..$^{10,21}$ Probably these peptides are agonistic to inhibitory neural pathways involved in ileal distention, ${ }^{22}$ just as in gastrointestinal hypomotility induced by rectal distension..$^{23}$ These findings reinforce our hypothesis, that activated mechanoreceptors due to rectal distention are responsible for increased frequency of tLESR, as shown in Table 1, irrespective of gastric distention. ${ }^{4}$

In their work Nellgård concluded that nocireceptors are involved too, besides activated rectal mechanoreceptors, in increasing the frequency of tLESR due to rectal distention. ${ }^{24}$ Excitatory neurotransmitters, just as inhibitory, are vital to nocireception activity. Nitric oxide (NO) is the most dominant nocireception neurotransmitter with inhibitory property, while Acetylcholine and Tachykinins are the main excitatory neurotransmitters, whose activity in stimulating the LES remain unknown. ${ }^{2}$ However, it has been reported that it is quasi impossible to analyse the nitrergic participation in animals, since they lack the enzyme neuronal NO-synthase, just as is the case of patients with acalasia. ${ }^{3}$ In response to LES contraction due to $\mathrm{Ca}^{2+}$-influx via $\mathrm{L}$ - $\mathrm{Ca}^{2+}$-channels, endogenous Ca-dependent NO is produced at the myenteric plexus of LES to modulate LES-muscular activity. ${ }^{25}$ On the contrary, an NO-receptor blocker prevents the occurrence of relaxing effects of constitutive-NO due to gastric distention; 
a finding previously published by our laboratory. ${ }^{8}$ In a similar fashion, tLSER remained unaltered in animals subjected to prior-bilateral pudendi and spinal cord resection (Table 3), suggesting a probable participation of the rectal sensory neuron and the parasympathetic tone afferent in modulating LEStone due to rectal distention. Surgical nerve sectioning thus prevents inhibitory interneuronal NO-dependent transmission.

Atropine and baclofen pre-treatments, respectively, prevented an increase in tLESR: $3.2 \pm 2.0$ vs $2.8 \pm 0.8$ and $1.9 \pm 0.9$ vs $2.8 \pm 0.8$ (Table 2). These results indicate that the mechanism of tLESR due to RD involves both muscarinic and GABA $\beta$ receptors, corroborating with the findings of Lehmann who showed that activating GABA $\beta$ receptors could offer a solution to treating clinically persistent GERD. ${ }^{13}$ As expected, activating GABA $\beta$ receptors provoked a negative agonist effect (Table 2). Similar to baclofen-protocols by Lehmann, ${ }^{13}$ Mittal $^{26}$ demonstrated that pre-treating humans and dogs with doses of atropine, significantly reduced the frequency of tLESR due to gastric distention. The incapacity of hexamethonium to abolish this increase in tLESR due to RD, suggests the absent

\section{REFERENCES}

1. Martin CJ, Dodds WJ, Liem HH, Dantas RO, layman RD, Dent J. Diaphragmatic contribution to gastroesophageal competence and reflux in dogs. Am J Physiol. 1992;263:G551-7.

2. Hershcovici T, Mashimo H, Fass R. The lower esophageal sphincter. Neurogastroenterol Motil. 2011;23:819-30.

3. Zerbib F, Bruley des Varannes S, Scarpignato C, Leray V, D'Amato M, Rozé C, et al. Endogenous cholecystokinin in postprandial lower esophageal sphincter function and fundic tone in humans. Am J Physiol. 1998;275(6):G1266-73.

4. Shafik A, El-Sibai O. Esophageal and gastric motile response to rectal distension with identification of a recto-esophagogastric reflex. Int J Surg Investig. 2000;1:373-9.

5. Whorwell PJ, Clouter C, Smith CL. Oesophageal motility in the irritable bowel syndrome. Br Med J (Clin Res Ed). 1981;282:1101-2.

6. Coremans G, Geypens B, Vos R, Tack J, Margaritis V, Ghoos $\mathrm{Y}$, et al. Influence of continuous isobaric rectal distension on gastric emptying and small bowel transit in young healthy women. Neurogastroenterol Motil. 2004;16:107-11.

7. Youle MS, Read NW. Effect of painless rectal distention on gastrointestinal transil of solid meal. Dig Dis Sci. 1984;29:902-6.

8. Palheta MS, Graça JR, Santos AA, Lopes LH, Palheta RC, Souza MA. The participation of the nitrergic pathway in increased rate of transitory relaxation of lower esophageal sphincter induced by rectal distension in dogs. Arq Gastroenterol. 2014;2:102-6.

9. Stephen AM, Haddad AC, Philipps SF. Passage of carbohydrate into the colon. Direct measurements in humans. Gastroenterology. 1983;85:589-95.

10. Piche T, Zerbib F, Varannes SB, Cherbut C, Anini Y, Roze C, Le Quellec A, et al. Modulation by colonic fermentation of LES participation of nicotinic ganglions, despite their abundant distribution all along the gastrointestinal tract and their pivot role in modulating gastric motility. ${ }^{27}$ Literature holds that medullar brainstem centers, in particular the NTS, integrate sensory information from the stomach and pharynx, thereby controlling the triggering of tLESR and consequent reflux episodes. ${ }^{19}$ Hence, reducing the frequency of reflux episodes, by inhibiting the triggering of tLESR, offers potential solutions for the treatment of reflux disease.

Our rectal distention-set up model explains the association of upper gut with low bowel symptoms simulating inflammatory such as bloating. Besides, this set up elucidates on the characterization of overlapping gut symptoms: frequent upper gastrointestinal symptoms alongside lower gut findings such as constipation and bloating. Basing on our results, this phenomenon involves neural, muscharinic and GABA $\beta$, but not nicotinic mediation. In spite of the multifactorial characteristic of gastro-esophageal reflux disease-pathophysiology, we can establish that tLESR plays a crucial role, significantly modified by other factors such as rectal distention.

function in humans. Am J Physiol Gastrointest Liver Physiol. 2000;278(4):G578-84.

11. Patrikios J, Martin CJ, Dent J. Relationship of transient lower esophageal sphincter relaxation to postprandial gastroesophageal reflux and belching in dogs. Gastroenterology. 1986;90:545-51.

12. Murray JA, Clouse RE, Conklin JL. Components of the standard oesophageal manometry. Neurogastroenterol Motil. 2003;15(6):591606.

13. Lehmann A, Jensen JM, Boeckxstaens GE. GABAB receptor agonism as a novel therapeutic modality in the treatment of gastroesophageal reflux disease. 2010;58:287-313.

14. Jensen J, Lehmann A, Uvebrant A, Carlsson A, Jerndal G, Nilsson $\mathrm{K}$, et al. Transient lower esophageal sphincter relaxations in dogs are inhibited by a metabotropic glutamate receptor 5 antagonist. Eur J Pharmacol. 2005;519(1-2):154-7.

15. Cox MR, Martin CJ, Dent J, Westmore M. Effect of general anesthesia on transient lower oesophageal sphincter relaxations in the dog. Aust NZ J Surg. 1988;58:825-30.

16. Sifrim D, Miau Y, Missotten T, Ni Y, Holloway R, Janssens J. Esophageal short $\neg$ ening and transient lower esophageal sphincter relaxations (TLESRs) in cats. Neurogastroenterol Motil. 1998;10:98.

17. Franzi SJ, Martin CJ, Cox MR, Dent J. Response of canine lower esophageal sphincter to gastric distension. Am J Physiol Gastrointest Liver Physiol. 1990;259:G380-5.

18. Stakeberg J, Lehmann A. Influence of different intragastric stimuli on triggering of transient lower oesophageal sphincter relaxation in the dog. Neurogastroenterol Motil. 1999;11(2):125-32.

19. Holloway RH. The anti-reflux barrier and mechanisms of gastro-oesophageal reflux. Best Pract Res Clin Gastroenterol. 2000;14:681-99. 
20. Maggi CA, Manzini S, Meli A. Contribution of neurogenic and myogenic factors in the response of rat proximal colon to distension. Am J Physiol Gastrointest Liver Physiol. 1987;252:G447-57.

21. Jain NK, Boivin M, Zinsmeister AR, Brown ML, Malagelada JR. Effect of ileal perfusion of carbohydrates and amylase inhibitor on gastrointestinal hormones and emptying. Gastroenterology. 1989;96:377-87.

22. Layer P, Peschel S, Schlesinger T, Goebell H. Human pancreatic secretion and intestinal motility: effects of ileal nutrient perfusion. Am J Physiol Gastrointest Liver Physiol. 1990;258:G196-201.

23. Qi H, Brining D, Chen JD. Rectal distension inhibits postprandial small intestinal motor activity partially via the adrenergic pathway in dogs. Scand J Gastroenterol. 2007;42(7):807-13.
24. Nellgård P, Jönsson A, Bojö L, Tarnow P, Cassuto J. Small-bowel obstruction and the effects of lidocaine, atropine and hexamethonium on inflammation and fluid losses. Acta Anaesthesiol Scand. 1996;40(3):287-92.

25. Salapatek AM, Fox-Threlkeld JE, Daniel EE. Mechanism of nitric oxide(NO)-induced LES relaxation involves intracellular calcium modulation (Abstract). Gastroenterology. 1996;110:A750.

26. Mittal RK, Holloway R, Dent J. Effect of atropine on the frequency of reflux and transient lower esophageal sphincter relaxation in normal subjects. Gastroenterol. 1995;109(5):1547-54.

27. Farré R, Sifrim D. Regulation of basal tone, relaxation and contraction of the lower oesophageal sphincter. Relevance to drug discovery for oesophageal dis-orders. Br J Pharmacol. 2008;153:858-69.

\section{How to cite:}

Graça JR, Neves JR, Silva SW, Okoba W. Rectal distention increases the frequency and duration of transient lower esophageal sphincter relaxations in anesthetized dogs - a putative rectoesophageal reflex. Rev Med UFC. 2019 jul-set;59(3):24-31. 